\title{
Perinatal Terminology
}

National Cancer Institute

\section{Source}

National Cancer Institute. Perinatal Terminology. NCI Thesaurus. Code C118466.

Terminology developed by a collaborative effort of the National Cancer Institute's Enterprise Vocabulary Services, the National Institute of Child Health and Human Development, and an international group of clinicians and informaticists to support the reporting of events in the perinatal population. 